\title{
A STUDY ON THE APPROXIMATE METHODS VS EXACT METHODS OF STRUCTURAL ANALYSIS
}

\author{
Mohammad Yasin Bhat \\ Department of Civil Engineering \\ SSM College of Engineering, Kashmir, India
}

\author{
Er. S. Tahir Hassan \\ Department of Civil Engineering \\ SSM College of Engineering, Kashmir, India
}

\begin{abstract}
The analysis of statically indeterminate structures, using the force and displacement methods, are considered as exact, as in such an analysis, the conformity and equilibrium conditions of the structure are satisfied exactly. However, the results of such a particular analysis represent the particular structural response only to the purpose up to which the model of the structure represents the particular structure. These methods are often reliably used, given as accurate as possible analytical model of the structure is employed within the analysis. But due to the difficulties related to exact analysis like time consuming computations of deflections and finding solutions of multiple equations, further complicated by the relative sizes of the members of the structure, the preliminary designs of indeterminate structures are often supported by the results of approximate analysis. Approximate analysis becomes very convenient to use within the planning phase of projects, when various alternative designs of the structure are considered and compared with reference to economic aspects. This text aims to match the results from the 2 methods obtained with numerical analysis on a frame structure. The approximate methods are expected to yield results within $25 \%$ of the precise solutions.
\end{abstract}

Keywords - Slope-Deflection Method, Moment Distribution Method, Portal Method, Cantilever Method, Staad Pro

\section{INTRODUCTION}

Structural analysis is an integral a part of any structural design. It involves the calculation of the response of the structure to the planning loads and possible deformations that it'll be required to resist during its lifetime. This necessitates the determination of the interior forces within the varied components of the structure and therefore the deformation of those components. Calculation of the interior forces of a structure will allow the structural designer to pick materials and dimensions of members that help the structure to securely resist loads with adequate strength and confirm that the probabilities of collapse are very small. Calculation of the deformation of the structure will permit the assessment of serviceability. Whether or not a structure is suitable for a specific purpose depends on its deformation, also as its strength. To analyse indeterminate structures, engineers use different methods both exact and approximate. Approximate methods however usually require a selected method for analysis of a specific sort of structure for a specific set of loading conditions. For instance, a special approximate method must be used for the analysis of an oblong frame under vertical loads than for the analysis of an equivalent frame subjected to lateral loads. Many structures constructed before 1960, were designed solely on the idea of approximate analysis. As such, numerous methods are figured out for the approximate analysis of indeterminate structures. On the opposite hand, exact methods give analysis which satisfy the equilibrium of forces and compatibility of deformations in the case of all the joints and supports In this study following exact methods have been used for analysis:

1. Slope-Deflection Method

2. Moment Distribution Method

The approximate methods used in the study are as follows

1. Portal Method

2. Cantilever Method

The results from these methods are obtained and arranged in the form of a table and then compared. Results obtained from Staad Pro V8i by Bentley have also been included. Let's first start with the exact methods of analysis and then proceed to the approximate methods.

\section{SLOPE DEFLECTION METHOD}

When endless beam is subjected to external loads, various internal moments develop, usually at the ends of its individual members. The slope-deflection equations relate the moments at the ends of a member to the rotations, and displacements of its ends to the external loads applied to the member. These equations are valid for prismatic members composed of linearly elastic material and subjected to small deformations. Although, the equations take under consideration the bending deformations of members, the deformations thanks to axial forces and shears are neglected.

Consider a beam as shown in the figure below. 


\section{International Journal of Engineering Applied Sciences and Technology, 2021 Vol. 6, Issue 2, ISSN No. 2455-2143, Pages 169-174 \\ Published Online June 2021 in IJEAST (http://www.ijeast.com)}

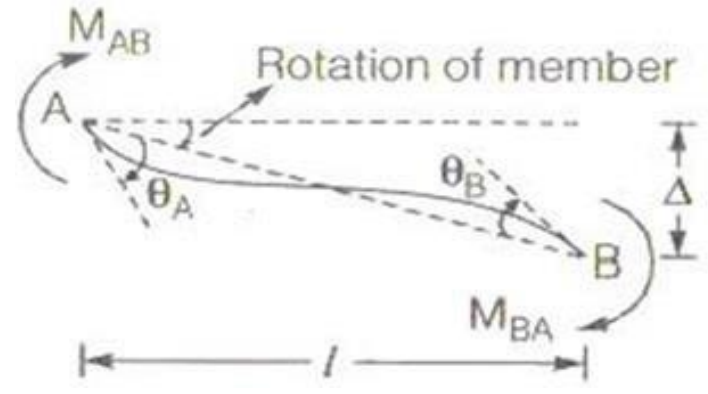

Fig. 1. Slopes and Deflection

The equations that relate the slope and deflection are given below.

$$
\begin{gathered}
M_{A B}=\overline{M_{A B}}+\frac{2 E l}{l}\left(2 \theta_{A}+2 \theta_{B}-\frac{3 \Delta}{l}\right) \\
M_{B A}=\overline{M_{B A}}+\frac{2 E l}{l}\left(2 \theta_{B}+2 \theta_{A}-\frac{3 \Delta}{l}\right)
\end{gathered}
$$

Where, L= Length of beam, EI= Flexural Rigidity

$\overline{M_{A B}}$ and $\overline{M_{B A}}$ are fixed-end moments at $\mathrm{A} \& \mathrm{~B}$ respectively.

$\mathrm{M}_{\mathrm{AB}} \& \mathrm{M}_{\mathrm{BA}}$ are final moments at $\mathrm{A} \& \mathrm{~B}$ respectively $\theta_{\mathrm{A}}$ and $\theta_{\mathrm{B}}$ are rotation of joint $\mathrm{A} \& \mathrm{~B}$ respectively. $\Delta=$ Settlement of support. The number of equations satisfying the joint equilibrium condition are going to be adequate to number of equations with rotational components and number of equations involving shear forces are going to be adequate to number of settlement equations.

[3] The slope-deflection method also can be used for the analysis of frames. Since the axial deformations of members of frames composed of common engineering materials are generally much smaller than deformations in bending, the axial deformations are again neglected within the analysis, and therefore the members are assumed to be inextensible. However, in some frames, the joints can undergo translations and such frames are termed as frames with sidesway, whereas the frames without joint translations are termed frames without sidesway. There also are frames which are subjected to loading which is symmetric with reference to axis of symmetry of structure.

The procedure for analysis essentially involves the following steps: (1) identifying the unknown joint displacements of the structure; (2) writing corresponding slope-deflection equations relating end moments of the members to the unknown joint displacements; (3) establishing the equilibrium equations of the structure in terms of end moments of members; (4) substituting the slope-deflection equations into the equilibrium equations and solving the resulting system of equations to work out the joint displacements; and (5) computing member end moments by substituting the values obtained in step 4 back to the slope-deflection equations. The sign convention used for this method is; Clockwise member end moments are considered as positive. Since a counter clockwise moment at an end of a member must act in a clockwise direction on the adjacent joint, the forgoing sign convention implies that clockwise moments on joints are considered positive.

\section{MOMENT DISTRIBUTION METHOD}

Moment distribution method is a form of displacement method that was developed by Hardy Cross in 1930s. Like the slopedeflection method, this method can be used only for the analysis of continuous beams and frames, taking into account their bending deformations only. The sign convention adopted here is the same as used previously for the slope-deflection method.

[3] The method begins by assuming that all members in a continuous beam are fixed at the internal supports or that all members in a frame are fixed at the joints. The fixed end moments for each member are then determined and the unbalanced moment at each joint is calculated as the sum of the fixed-end moments of all the members entering the joint. Each joint is then released one at a time, by applying a balancing moment to the joint, equal and opposite to the unbalanced moment at that joint. This balancing moment is then distributed to the members framing into the joint according to their relative rotational stiffness, hence the name. When a balancing moment $\mathrm{M}_{\mathrm{bal}}$ is applied at one end (say A) of a member, a carry-over moment is induced at the far end of the member (at B). The carry-over factor (COF) is the ratio of the carry-over moment at $\mathrm{B}$ to the balancing moment at $\mathrm{A}$. This results in new unbalanced moments at adjacent joints. The joint is then re-locked and an adjacent joint is unlocked and balanced. This process of distribution continues until the unbalanced moment at each joint is small enough to ignore, and the final-end moments and end rotations of each member are determined. It is an iterative process that approaches the final solution by successive approximation. This method is relatively simple, repetitive and suitable for manual calculation. The value of COF is 0.5 , if the far end of member is fixed and 0 , if the far end of member is hinged. The fraction of a balancing moment at a joint that is distributed to a particular member is called the distribution factor for that member, and is the ratio of the rotational stiffness of the member to the joint stiffness. For a joint with $n$ members framing into it, the DF for the $i$-th member is;

$\mathrm{DF}_{i}=\mathrm{k}_{i} / \mathrm{K}_{\mathrm{J}}$

where $K_{J}$ is joint stiffness which is the sum of the rotational stiffness of each member at that joint and is equal to the moment required to rotate the joint through an angle of 1 radian. The sum of all the distribution factors at the joint is 1 . 


\section{International Journal of Engineering Applied Sciences and Technology, 2021 \\ Vol. 6, Issue 2, ISSN No. 2455-2143, Pages 169-174 \\ Published Online June 2021 in IJEAST (http://www.ijeast.com)}

Frames in which joint translation is prevented may be analysed using this method in the same way as for continuous beams. The same is true for frames that are symmetrical and are symmetrically loaded since such frames will not sway. In a frame where joint translation is not prevented by lateral restraints, sidesway will occur if the frame is not symmetric, if the vertical loading is not symmetric or if lateral loads are applied to the frame. A superposition approach is to be used to include the effects of joint translation, whereby sway is initially ignored by introducing a fictitious lateral support, and the moment distribution $\mathrm{M}_{0}$ caused by applied loads is determined. The reaction that develops at the fictitious support $\mathrm{R}_{0}$ is calculated. Next, the frame with the fictitious support is subjected to an arbitrary sway (support settlements) and the moments caused by this sway $M_{\Delta}$ are determined. The reaction at the fictitious support $\mathrm{R}_{\Delta}$ is determined from statics. In the real frame, the reaction at the fictitious support must be zero, and so;

$\mathrm{R}_{0}+\mathrm{f}_{\Delta} \mathrm{R}_{\Delta}=0$

where $f_{\Delta}$ is the ratio of the actual sway to the arbitrary sway. The magnitude of the sway required to satisfy above equation is determined and the corresponding sway moments $\mathrm{f}_{\Delta} \mathrm{M}_{\Delta}$ are established. The moment at any point in the sway frame $\mathrm{M}$ is obtained by adding the moment calculated at that point without sway to the moment calculated due to sway.

\section{APPROXIMATE METHODS}

In order to work out the reactions and internal forces of an indeterminate structure, we not only require equilibrium equations but also some additional equations, whose number must equal the degree of indeterminacy of the structure. In an approximate analysis, these additional equations are established by using engineering judgement to form simplifying assumptions about the response of the structure. The entire number of those assumptions must be adequate to the degree of indeterminacy of the structure such that each of those assumptions gives an independent relationship among the unknown variables. The behavior of rectangular building frames is different under lateral and vertical loads, so different assumptions are made for each of them. [2] Following are the assumptions that are made for every girder in an exceedingly rectangular frame which is subjected to series of vertical loads.

- "If the girder ends are liberated to rotate, as in the case of a simply supported girder, the inflection points would occur at the ends.

- If the girder ends were completely fixed against rotation, it can be shown that the inflection points would occur at a distance of $0.211 \mathrm{~L}$ from each end of the girder where $\mathrm{L}$ is the length. And, if the ends are only partially restrained, the inflection points are located at a distance of $0.1 \mathrm{~L}$ from each end of the girder.

- The girder axial force is zero."

For frames under lateral loads only, following two methods are used.

\section{A. Portal Method}

The portal method was initially developed by A. Smith in 1915 and is employed in the analysis of structural frames that are relatively small. Following assumptions are made in the portal method:

- An inflection point is located at the middle of each member of the frame.

- On each story of the frame, interior columns carry twice as much shear as exterior columns.

[2] Following procedure is employed in portal method:

1. "Draw a rough sketch of the simplified frame obtained by inserting an internal hinge at the middle of each member.

2. Column shears are determined for each storey of the frame.

3. Draw FBD of all members and joints of the frame, showing the external loads and the end shears of the columns computed earlier.

4. Determine column moments by applying the equations of condition that the bending moment is zero at the column mid height, as there is a hinge. The magnitude of the column end moments is equal to the magnitude of the column shears times half the column height.

5. Determine the girder axial forces, moments, and shears starting at the top and continuing to the bottom.

6. Determine column axial forces, starting at the top story by applying the equilibrium equations successively to the free body of each joint.

7. Using the equilibrium equations, check the calculations performed in the analysis. If the values are correct, then the equilibrium equations should be satisfied."

\section{B. Cantilever Method}

[1] The cantilever method was initially developed by A.C Wilson in 1908. Contrary to portal method, this method is used in the analysis of structural frames that are tall. Again, the two assumptions made here as follows:

- An inflection point is located at the middle of each member of the frame.

- On each storey of the frame, the axial forces in columns are linearly proportional to their distances from the centroid of the cross-sectional areas. This is true for all the columns on a particular storey. 


\section{International Journal of Engineering Applied Sciences and Technology, 2021 \\ Vol. 6, Issue 2, ISSN No. 2455-2143, Pages 169-174 \\ Published Online June 2021 in IJEAST (http://www.ijeast.com)}

[2] Following steps are followed in the analysis by the cantilever method:

1. "Draw a sketch of the simplified frame obtained by inserting an internal hinge at the midpoint of each member of the given frame.

2. Determine column axial forces. For each story of the frame:

a) Pass a horizontal section through the internal hinges at the column mid heights, that cuts the frame into two equal portions.

b) Draw a FBD of the portion of the frame above the section. As the section passes through the columns at the internal hinges, only internal shears and axial forces act on the free body at the points where the columns have been bisected.

c) Centroids are determined of the columns on the storey that is being considered.

d) Assuming that the axial forces in the columns are proportional to their distances from the centroid, determine the column axial forces by applying the moment equilibrium equation to the free body of the frame above the section. To eliminate the unknown column shears from the equilibrium equation, the moments should be summed about one of the internal hinges at the column mid heights through which the section has been passed.

3. Draw FBD of all the members and joints of the frame showing the external loads and the column axial forces computed in the previous step.

4. Determine girder shears and moments.

5. Determine the column moments and shear. Calculate the shear at the upper end of the column by dividing the column moment by half the column height.

6. Then the axial forces are determined using equations of equilibrium.

7. Lastly, check the calculations using the equilibrium equations."

\section{NUMERICAL ANALYSIS AND CALCULATIONS}

Numerical analysis was done on a single storey frame as shown below. The values of various responses calculated is as shown in table 1 .

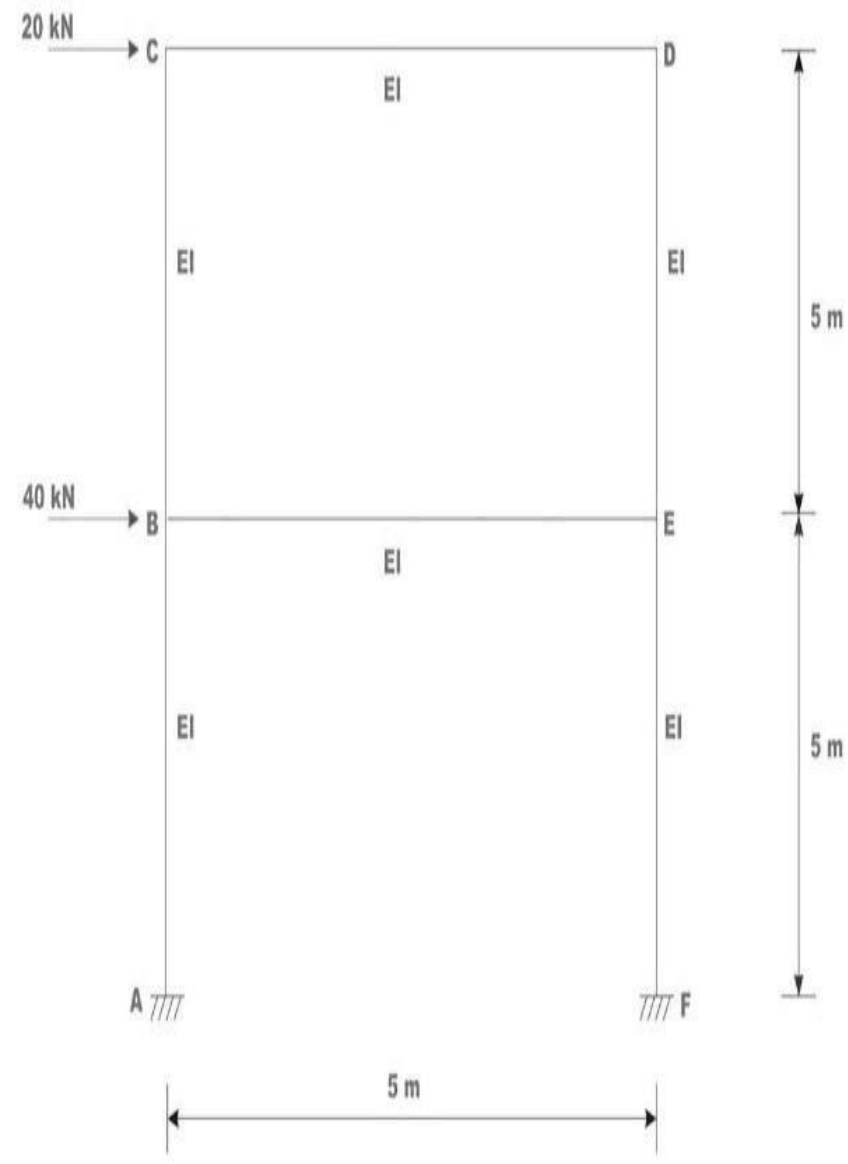

Fig. 2. Frame A

The values have been compared in the form a graph as shown.

(Note:

1. Instead of the negative values of the quantities, positive values have been taken for the sake of uniformity.

2. Due to limitations of data sheet program, the subscripts couldn't be used and thus they appear next to the moment symbol $\mathrm{M}$ and the shear symbol $\mathrm{V}$. e.g., $\mathrm{M}_{\mathrm{CD}}$ has been written as $\mathrm{MCD}, \mathrm{V}_{\mathrm{CD}}$ has been written as VCD.) 
International Journal of Engineering Applied Sciences and Technology, 2021

Vol. 6, Issue 2, ISSN No. 2455-2143, Pages 169-174

Published Online June 2021 in IJEAST (http://www.ijeast.com)

\begin{tabular}{|c|c|c|c|c|c|c|}
\hline Storey & & $\begin{array}{c}\text { Slope } \\
\text { Deflection } \\
\text { Method }\end{array}$ & $\begin{array}{c}\text { Moment } \\
\text { Distribution } \\
\text { Method }\end{array}$ & Portal Method & $\begin{array}{l}\text { Cantilever } \\
\text { Method }\end{array}$ & $\begin{array}{c}\text { Staad Pro V8i by } \\
\text { Bentley }\end{array}$ \\
\hline \multicolumn{7}{|c|}{ Moments in beams (kN-m) } \\
\hline \multirow[t]{2}{*}{ Top } & $\mathrm{M}_{\mathrm{CD}}$ & -32.72 & -32.54 & -25.00 & -25.00 & -32.71 \\
\hline & $\mathrm{M}_{\mathrm{DC}}$ & -32.72 & -32.54 & -25.00 & -25.00 & -32.75 \\
\hline \multirow[t]{2}{*}{ Bottom } & $\mathrm{M}_{\mathrm{BE}}$ & -79.09 & -79.54 & -75.00 & -75.00 & -78.79 \\
\hline & $\mathrm{M}_{\mathrm{EB}}$ & -79.09 & -79.54 & -75.00 & -75.00 & -78.85 \\
\hline \multicolumn{7}{|c|}{ Moments in columns (kN-m) } \\
\hline \multirow[t]{4}{*}{ Top } & $\mathrm{M}_{\mathrm{BC}}$ & 17.27 & 17.06 & 25.00 & 25.00 & 17.22 \\
\hline & $\mathrm{M}_{\mathrm{CB}}$ & 32.72 & 32.54 & 25.00 & 25.00 & 32.71 \\
\hline & $\mathrm{M}_{\mathrm{DE}}$ & 32.72 & 32.54 & 25.00 & 25.00 & 32.75 \\
\hline & $\mathrm{M}_{\mathrm{ED}}$ & 17.27 & 17.06 & 25.00 & 25.00 & 17.32 \\
\hline \multirow[t]{4}{*}{ Bottom } & $\mathrm{M}_{\mathrm{AB}}$ & 88.18 & 88.52 & 75.00 & 75.00 & 88.49 \\
\hline & $\mathrm{M}_{\mathrm{BA}}$ & 61.81 & 62.09 & 75.00 & 75.00 & 61.66 \\
\hline & $\mathrm{M}_{\mathrm{EF}}$ & 61.81 & 62.09 & 75.00 & 75.00 & 61.53 \\
\hline & $\mathrm{M}_{\mathrm{FE}}$ & 88.18 & 88.52 & 75.00 & 75.00 & 88.33 \\
\hline \multicolumn{7}{|c|}{ Shears in beams $(\mathrm{kN})$} \\
\hline Top & $\mathrm{V}_{\mathrm{CD}}$ & -13.09 & -13.02 & -10.00 & -10.00 & -13.09 \\
\hline Bottom & $\mathrm{V}_{\mathrm{BE}}$ & -31.64 & -31.82 & -30.00 & -30.00 & -31.55 \\
\hline \multicolumn{7}{|c|}{ Shears in columns $(\mathrm{kN})$} \\
\hline \multirow[t]{2}{*}{ Top } & $\mathrm{V}_{\mathrm{CB}}$ & 9.998 & 9.920 & 10.000 & 10.000 & 9.986 \\
\hline & $\mathrm{V}_{\mathrm{DE}}$ & 9.998 & 9.920 & 10.000 & 10.000 & 10.010 \\
\hline \multirow[t]{2}{*}{ Bottom } & $\mathrm{V}_{\mathrm{AB}}$ & 29.998 & 30.122 & 30.000 & 30.000 & 30.030 \\
\hline & $\mathrm{V}_{\mathrm{EF}}$ & 29.998 & 30.122 & 30.000 & 30.000 & 29.970 \\
\hline
\end{tabular}

Table 1. Values from different methods for Frame A

Graphical Comparison

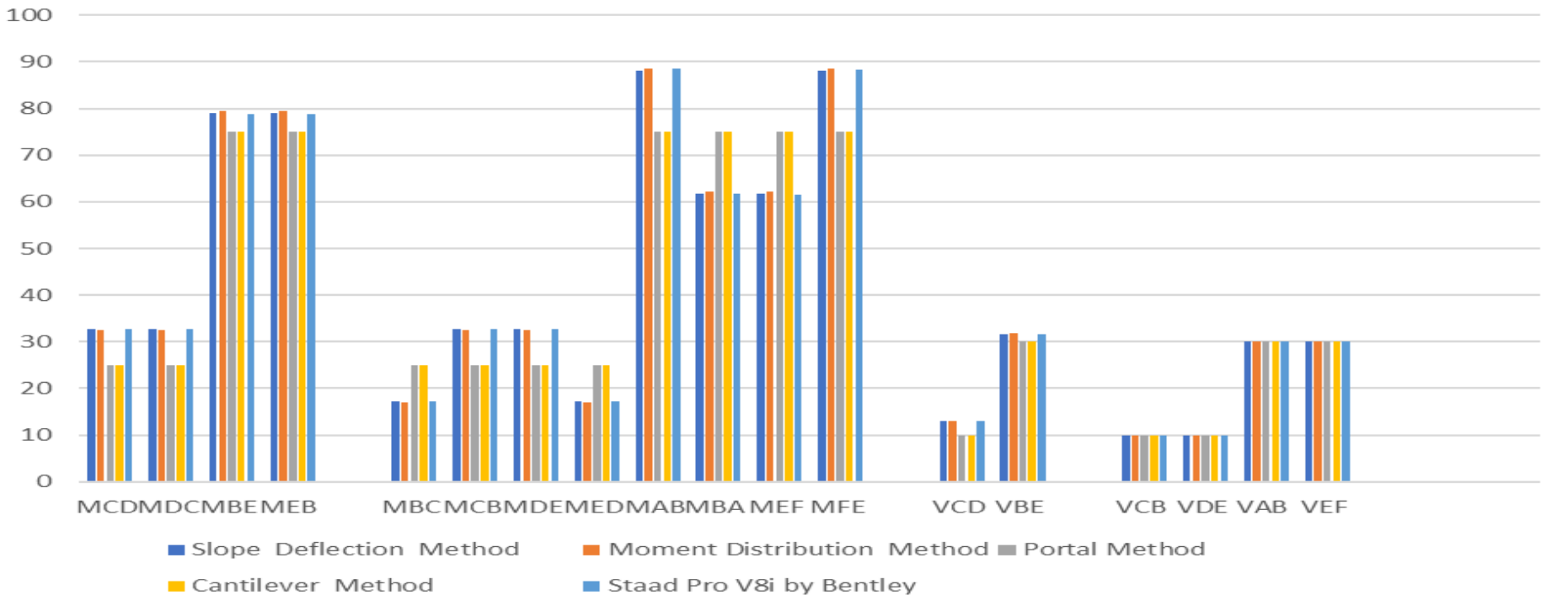

Graph 1. 


\section{International Journal of Engineering Applied Sciences and Technology, 2021 \\ Vol. 6, Issue 2, ISSN No. 2455-2143, Pages 169-174 \\ Published Online June 2021 in IJEAST (http://www.ijeast.com)}

\section{CONCLUSIONS}

As can be seen, the values from the exact methods are very similar and close to the values obtained from Staad Pro. The values from the approximate methods are close to the values from exact methods with maximum deviation of $23.4 \%$ from the mean of the values obtained with exact methods (moment in the top beam CD) and a minimum deviation of $0.09 \%$ from the mean of the values obtained with exact methods (shear in top column EF).

So, it can be concluded that for preliminary analysis of a project, approximate methods can be conveniently used for evaluating relative economy of the several alternative designs of the structure.

\section{ACKNOWLEDGEMENTS}

I would like to express my sincere and heartfelt gratitude to Er. Tahir for inspiring and helping me to work on this project. I would like to thank my friend Mujeeb for the syntactic aspects of this paper. I would also like to extend my gratitude to my colleague Farhan for helping me with some of the technicalities of the study.

\section{REFERENCES}

[1] Hibbler R. C, 2018: Structural Analysis Ninth Edition in SI Units, Pearson

[2] Kassimali Aslam, 2011: Structural Analysis Fourth Edition, SI Illinois University - Carbondale SI Edition prepared by Amit Prashant, Indian Institute of Technology, Kanpur

[3] Gianluca Ranzi and Raymond Ian Gilbert, 2015: Structural Analysis Principles, Methods and Modelling, CRC Press

[4] Wang C. K. 1998: Intermediate Structural Analysis Mc Graw -Hill Publications 5th edition

[5] Conner Jerome, and Faraji Susan, 2016: Fundamentals of Structural Engineering Springer

[6] McCormac C. Jack: Structural Analysis

[7] Nash, William A, 2004: Theory and Problems of Strength of materials, Tata McGraw Hill, New Delhi

[8] West: Fundamentals of Structural Analysis

[9] John M. Biggs: Introduction to Structural Engineering

[10] Noris \& Wilbur: Structural Mechanics

[11] Jindal R. L: Determinate Structures

[12] Reddy, C.S, 2003: Basic Structural Analysis, Tata McGraw Hill, New Delhi 